\title{
Effectiveness and compliance of an oscillating-rotating toothbrush in patients with dental implants: a randomized clinical trial
}

\author{
Giuseppe Allocca ${ }^{1}$, Diana Pudylyk ${ }^{1}$, Fabrizio Signorino ${ }^{1 *}$ (D) Giovanni Battista Grossi ${ }^{2}$ and Carlo Maiorana ${ }^{1}$
}

\begin{abstract}
Background: The aim of this randomized clinical trial was to assess the efficacy of an oscillating-rotating toothbrush in reducing plaque and inflammation around dental implants.

Methods: Eighty patients presenting dental implants were enrolled in this study and assigned randomly to two different groups: 40 patients in the test group and 40 in the control one. Each patient in the test group received an oscillating-rotating toothbrush while in the control group patients kept using the manual toothbrush. Furthermore, the test group received a special toothbrush head designed for dental implants and another one for natural teeth. Domiciliary oral hygiene instructions were given to both groups. Periodontal parameters like plaque index (PI), bleeding on probing (BoP), and probing pocket depth (PPD) were recorded th the baseline and after 1 and 3 months.

Results: At the end of the study, the difference of plaque and bleeding indices with the baseline was statistically significant for both test and control groups $(P<0.0001)$. Implant sites showed higher values of both BoP and PI when compared to the natural teeth. In the second part of the study, comparing the 1-3-month period, the oscillatingrotating toothbrush was effective in reducing new plaque formation $(P<0.0001)$ and bleeding $(P<0.0001)$ both at the implant sites and the dental sites comparing to manual ones $(P>0.05)$. No significant differences were appreciated concerning the PPD.
\end{abstract}

Conclusions: The oscillating-rotating toothbrush can be successfully used for the plaque and bleeding control of the peri-implant tissues.

Keywords: Dental implant, Domiciliary hygiene, Electric toothbrush, Implant maintenance, Oral hygiene

\section{Background}

Dental implants became one of the most accepted treatments for the rehabilitation of partial or complete edentulism [1]. However, inflammatory processes may still occur due to the presence of the implant itself [2]. It is well known that peri-mucositis and peri-implantitis are strictly related to the presence of plaque on the surface of the implant-prosthetic complex, which lead respectively to the inflammation of peri-implant soft tissues and

\footnotetext{
* Correspondence: fabroski@hotmail.it

${ }^{1}$ Center for Edentulism and Jaw Atrophies, Maxillofacial Surgery and

Dentistry Unit, Fondazione IRCCS Cà Granda - Ospedale Maggiore Policlinico,

University of Milan, Via Commenda 10, 20122 Milan, Italy

Full list of author information is available at the end of the article
}

the bone loss around the implant neck area [3, 4]. The problem of implant maintenance must be taken in serious consideration even before the dental implant placement. Many risk factors have been associated to peri-implantitis such as smoke, diabetes, and a history of periodontal disease [5-8]. Furthermore, the prevalence of this pathology is rising. It has been estimated, in fact, that a range from 10 to $43 \%$ of all implants placed today will have some form of peri-implantitis in about 10 years $[9,10]$. Many authors associated the microbiological flora responsible of peri-implantitis to the one associated to periodontal disease, while others confuted this hypothesis [11]. 
Many techniques and protocols have been introduced for the treatment of peri-implantitis; however, the topic is still debated and the different rates of success of various treatments still suggest that a good prevention must still be preferred [12]. The presence of bacterial microfilm on the implant surface has been individuated as the primary cause of the pathologic mechanism. As well as in the teeth, mechanical removal represents the only treatment able to remove the microfilm and toothbrush and dental floss are the only effective domiciliary devices able to remove plaque from the teeth and dental implant. Mouth rinses or other methods may enhance periodontal indices but only when associated to an effective primary mechanic removal device. It has also been proved how both manual and electric toothbrushes are effective in the plaque removal [13]. Several authors comparing the two devices were not able to find any differences in term of clinical results, while others found advantages for one technique with respect to the other [14-17]. Patients with motor problems and elderly may found benefit in using the electric toothbrush, which does not require the same level of manual skills as the manual one $[18,19]$. Recently, there has been introduced a new type of electric toothbrush, with a visual-sound system, showing the correct pressure to apply when brushing and the exact amount of time necessary to complete one or half dental arch. Special designed toothbrush heads for different areas of the mouth and different surfaces, like dental implants, have recently been introduced for electric toothbrushes without a clear scientific support. The present study aims to investigate the efficacy of an oscillating-rotating toothbrush using a dedicated designed head, in patients with dental implants.

\section{Methods}

The study was conducted between September 2015 and June 2017 at Implantology Department of Policlinic Hospital, University of Milan, Milan. It was designed as a monocentric randomized clinical study according to the STROBE criteria. Eighty patients who underwent dental implant rehabilitation were selected for this study. At the screening visit, subjects were asked to read and sign a written informed consent and personal medical history and demographic information was obtained. Dental implants must have been placed at least 1 year before the recruitment; other inclusion criteria were age between 18 and 90 and a good general health. Patients with orthodontic therapy or removable prosthesis, including overdenture type, were not included in the study as well as non-controlled diabetic or heavy smoker ( $>10$ cigarettes) patients. The patients were already following a maintenance program after the implant placement; however, all of them were using the manual toothbrush for domiciliary oral hygiene. After being included in the study, each patient underwent periodontal (North Carolina) and peri-implant (perio probe) charting and recording of bleeding and plaque indexes (gingival bleeding index and plaque control record). Gingival bleeding index and plaque control record were recoded as the presence/absence of bleeding or plaque on four sites per tooth/implant. In order to detect the plaque, a disclosing agent was used. Sequentially, dental hygienist performed professional prophylaxis to establish a plaque free dentition. A software program randomly assigned 40 patients for both test and control groups. The electric toothbrush (Oral- $\mathrm{B}^{\circ}$ ProfessionalCare 6000 with Bluetooth; Oral- $\mathrm{B}^{\circ}$, Procter \& Gamble, Cincinnati, $\mathrm{OH}$, United States) was introduced to patients of the test group, and instructions were given. According to the producer instruction, the procedure must have lasted not less than $2 \mathrm{~min}$, using a timer set on $30 \mathrm{~s}$ for quadrant, twice/day. Furthermore, all the patients received a special toothbrush head designed for dental implants (Interspace; Oral- $\mathrm{B}^{\circ}$ ) together with another one for the natural teeth (Precision clean; Oral- ${ }^{\circ}$ ) (Fig. 1). The patients of the control group did not change the manual toothbrush as a domiciliary oral hygiene device and received instructions of the modified Bass technique. The recommended time for toothbrushing was at least $90 \mathrm{~s}$, twice a day. Patients of both groups received all the information in a paper copy. Once verified that the patients understood the instructions, new appointments were scheduled after 1 and 3 months. Bleeding on probing, plaque index, and probing depth were recorded at each visit on both dental implants and natural teeth. The entire

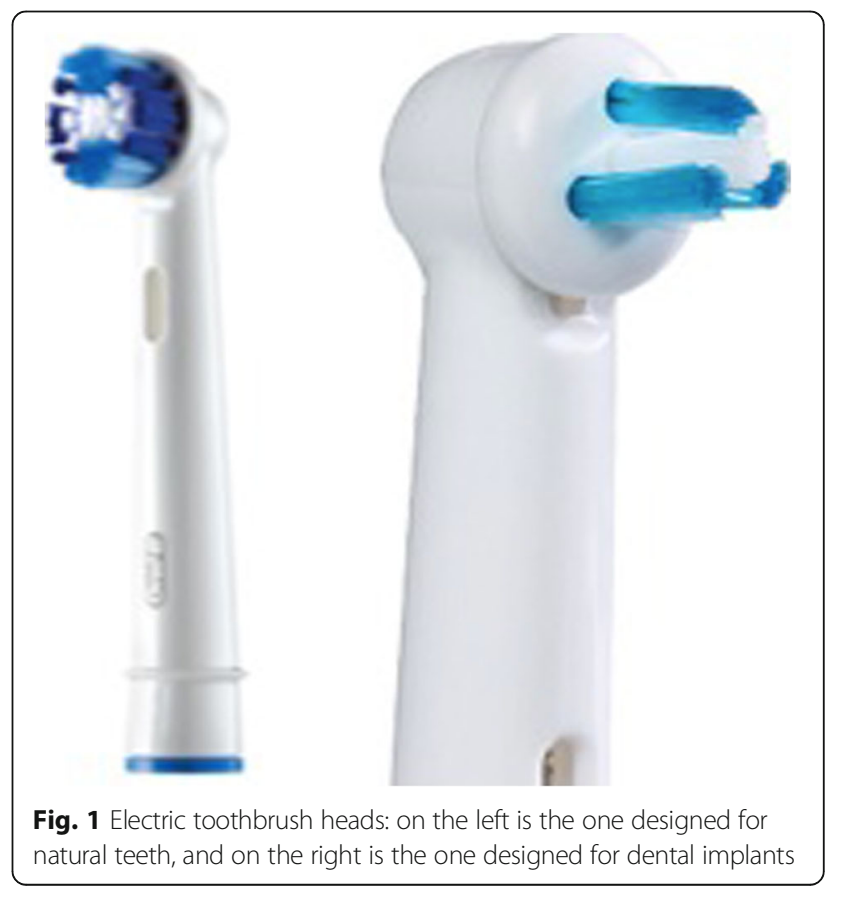


sample had to use the same toothpaste to reduce the variability of the results.

\section{Statistical analysis}

Mean scores of all clinical indices for each subject were calculated separately for dental implants and natural teeth. The final data analysis was performed for those subjects who completed the study. The Student's $t$ test and the Mann-Whitney $U$ test were used to evaluate whether any statistically significant differences were present between the two groups at each time point, and the Wilcoxon signed-rank test was performed to verify if any statistically significant changes occurred from baseline within each group. A total sample size of 74 patients (37 per group) achieves $81 \%$ power to detect a difference of 0.2 between the differences of group means with group standard deviations of 0.3 . $P$ values $<0.05$ were considered statistically significant.

\section{Results}

Seventy-eight patients successfully completed the study (45 women and 33 men aged from 31 to 76 years old) (Fig. 2). Two patients of test group did not show up both at the first and second controls. No patients were excluded or showed complications or adverse reaction. Results are shown in Table 1 . The average number of implants per patients was $4.8 \pm 3.4$ in the control group and $4.4 \pm 2.9$ in the test one. Single crowns, implant-supported bridges, and Toronto bridge were included in both of the study groups. The values taken in consideration were recorded for both the dental implants and the rest of the dentition and compared at each time. All dental implant index values were higher when compared to the natural teeth ones while no differences were appreciable concerning the PPD. The study provided data for the test and control groups at three different time points. Analyzing the results, it can be observed for both groups a high decrease of BoP and PI values after 1 month after the baseline, related to the prophylaxis performed by dental hygienist.

The second part of the study described the re-colonization of dental implants and teeth surfaces: this was related to the proper use of oral hygiene devices, showing the effective difference of the manual and electric toothbrushes in preventing the new plaque formation and the consequent inflammation status.

\section{Plaque index}

The difference of PI recorded around implants at the beginning and the end of the study was statistically significant for both control and test groups $(P<0.0001)$. Observing in detail the second part of the study in Fig. 3, it was possible to observe how the test group kept reducing $(P<0.0001)$ while the control showed a mild increase $(P=0.68)$. Comparison at 3 months showed statistical significance $(P<0.05)$.

In Fig. 4 is shown the PI recorded around natural teeth: in this case, comparing the baseline with the data collected after 3 months was possible to observe high statistical significance only for the test $(P<0.0001)$ and significance for the control $(P<0.05 ; \quad P=0.031)$. Highlighting the second part, the different trend of test and control lines confirmed the higher performances of test devices $(P<0.0001)$ compared to the control that showed a mild increase $(P=0.16)$. Comparison between the two groups at 3 months was highly statistically significant $(P<0.0001)$.

\section{Bleeding on probing}

The difference between the BoP recorded on dental implant sites at baseline and the end of the study showed statistical significance for both the test and

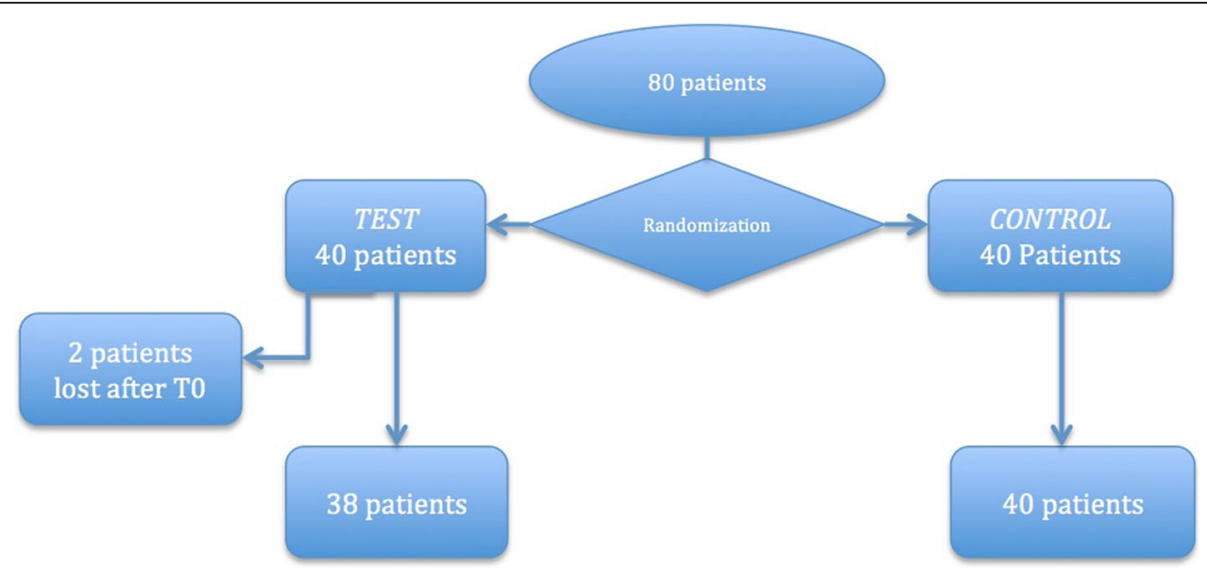

Fig. 2 Patients' population flow chart 
Table 1 BoP, PI, and PPD mean values at baseline, 1 month, and 3 months

\begin{tabular}{llll}
\hline & Baseline & 1 month & 3 months \\
& T0 & T1 & $22.18 \% \pm 11.06 \%$ \\
\hline BoP implants, test & $46.55 \% \pm 18.41 \%$ & $32.31 \% \pm 13.27 \%$ & $19.11 \% \pm 17.30 \%$ \\
BoP implants, control & $32 \% \pm 24.88 \%$ & $19.84 \% \pm 15.52 \%$ & $6.5 \% \pm 5.18 \%$ \\
BoP teeth, test & $18.81 \% \pm 15.93 \%$ & $8.76 \% \pm 8.11 \%$ & $16.38 \% \pm 11.79 \%$ \\
BoP teeth, control & $21.61 \% \pm 15.38 \%$ & $15.50 \% \pm 12.21 \%$ & $15.52 \% \pm 12.29 \%$ \\
PI implants, test & $53.71 \% \pm 14.72 \%$ & $33.65 \% \pm 12.57 \%$ & $32.68 \% \pm 16.02 \%$ \\
PI implants, control & $50.13 \% \pm 27.39 \%$ & $28.66 \% \pm 16.26 \%$ & $14.5 \% \pm 6.74 \%$ \\
PI teeth, test & $33.15 \% \pm 13.49 \%$ & $20.76 \% \pm 10.16 \%$ & $35.77 \% \pm 15.80 \%$ \\
PI teeth, control & $41.34 \% \pm 17.20 \%$ & $32.26 \% \pm 15.02 \%$ & $2.61 \mathrm{~mm} \pm 0.54 \mathrm{~mm}$ \\
PPD implants, test & $2.73 \mathrm{~mm} \pm 0.59 \mathrm{~mm}$ & $2.67 \mathrm{~mm} \pm 0.5 \mathrm{~mm}$ & $2.21 \mathrm{~mm} \pm 0.66 \mathrm{~mm}$ \\
PPD implants, control & $2.4 \mathrm{~mm} \pm 0.97 \mathrm{~mm}$ & $2.22 \mathrm{~mm} \pm 0.57 \mathrm{~mm}$ & $1.69 \mathrm{~mm} \pm 0.4 \mathrm{~mm}$ \\
PPD teeth, test & $1.7 \mathrm{~mm} \pm 0.47 \mathrm{~mm}$ & $1.69 \mathrm{~mm} \pm 0.38 \mathrm{~mm}$ & $2.04 \mathrm{~mm} \pm 0.52 \mathrm{~mm}$ \\
PPD teeth, control & $2.01 \mathrm{~mm} \pm 0.67 \mathrm{~mm}$ & $1.93 \mathrm{~mm} \pm 0.58 \mathrm{~mm}$ & \\
\hline
\end{tabular}

Data are shown as mean \pm standard deviation

test electric toothbrush with the two different heads designed for dental implants and natural teeth, control manual toothbrush

control groups $(P<0.0001)$ (Fig. 5). Analyzing in detail the 1-3-month period, it was observed how only the test group showed a statistical significance $(P<0.0001)$ while the control lost it $(P=0.709)$. At 3 months, no significative differences between the two groups were observed $(P=0.564)$.

Analog situation could be observed in Fig. 6, representing BoP around the natural teeth. In this case, the difference with the baseline were significant for both groups $(P<0.0001$ and $P=0.007$ respectively for test and control). In the second part of the observation period (1-3-month period), it was possible to detect an increase for the control $(P=0.342)$ while the test kept decreasing, even if slightly $(P<0.05 ; P$ $=0.0021)$. The comparison between the test and control groups after 3 months showed a statistical significance $(P<0.05)$.

\section{Pocket probing depth}

No differences during the time points were observed in both test and control groups as clearly shown in Figs. 7 and 8. It was possible to observe a reduction of PPD of $0.15 \mathrm{~mm}$ between the beginning and end of the study around dental implants on both test and control groups.

\section{Discussion}

This 3-month study aimed to demonstrate the efficacy of an electric toothbrush in reducing plaque and gingival inflammation around dental implants

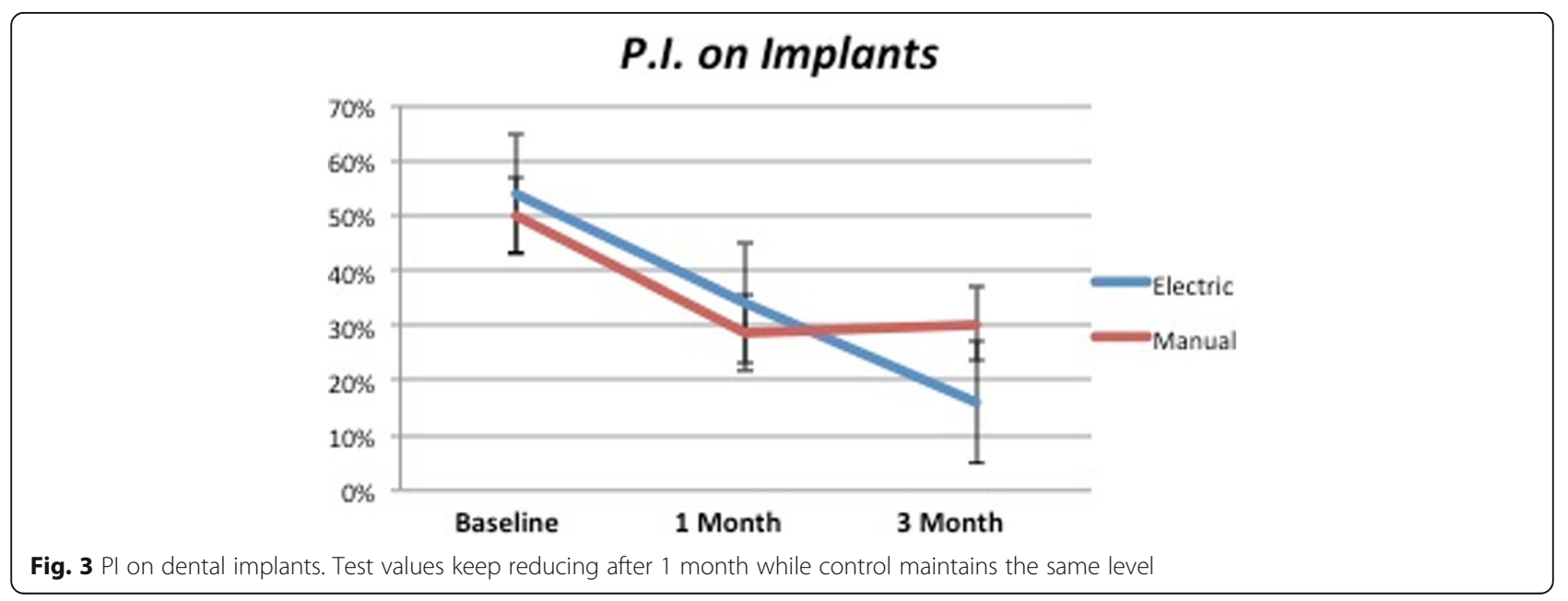




\section{P.I. on Teeth}

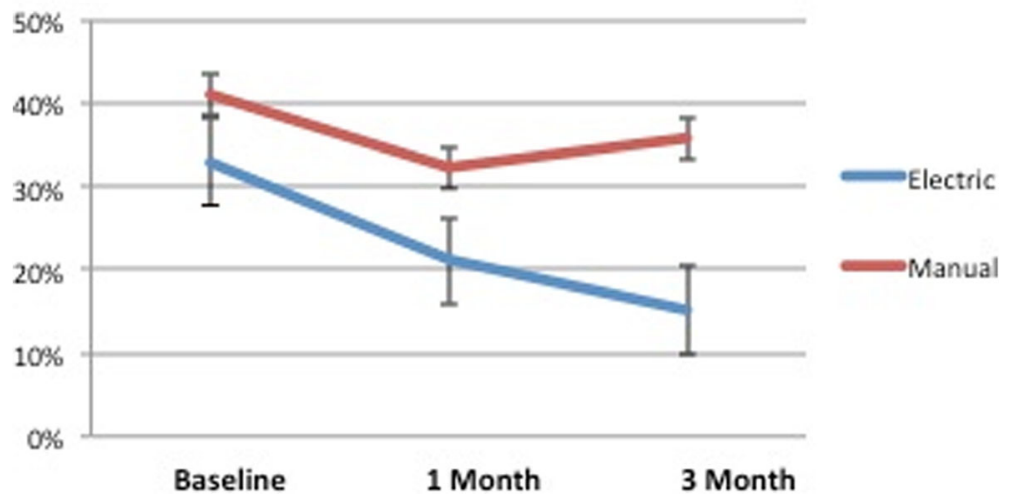

Fig. $4 \mathrm{Pl}$ on natural teeth. After 1 month, the test group showed mild reduction while control a light improvement

and natural teeth. To better understand the different data collected around two different anatomical structures, we decided to collect data separately. Analyzing our results, it is possible to observe how the mean values for probing, bleeding, and plaque index were bigger for dental implants. According to literature, it was expected to find deeper probing for dental implants [20]. Many authors associated this to the different kind of attachment and the different orientation of periodontal fiber around dental implants [21-23]. The electric toothbrush has widely been described as a preventive option in the maintenance of peri-implant tissues [24-28]. However, many authors did not observe any differences between the manual and electric toothbrush, and for this reason, the topic is still controversial $[17,19]$. In the present study, the manual toothbrush seemed to maintain the values achieved with the professional prophylaxes; however, a mild increase of both PI and BoP was detected after 3 months. The choice to perform prophylaxis on all patients after baseline index recording was done in order to bring the patients at the same level and reduce the variability of the study according to several authors $[29,30]$. As a direct consequence, all the values recorded in both groups resulted to be extremely decreased at the second time point, after 1 month. However, the data collection at the third time point 3 months after the baseline made possible to analyze the new plaque formation trend in both groups and verify the different devices' efficacy on both teeth and implant. The evolution observed over time can be related also to the presence of peri-implant and periodontal pockets. Despite that the average values of PPD were lower

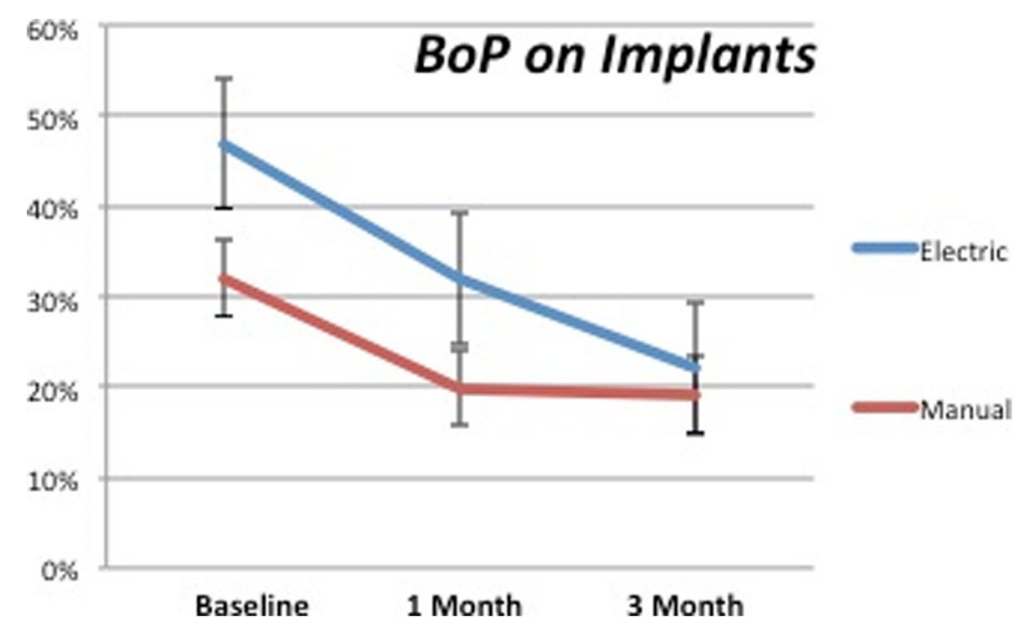

Fig. 5 BoP on dental implants. It can be observed how the values keep decreasing after 1 month only in the test group 


\section{BoP on Teeth}

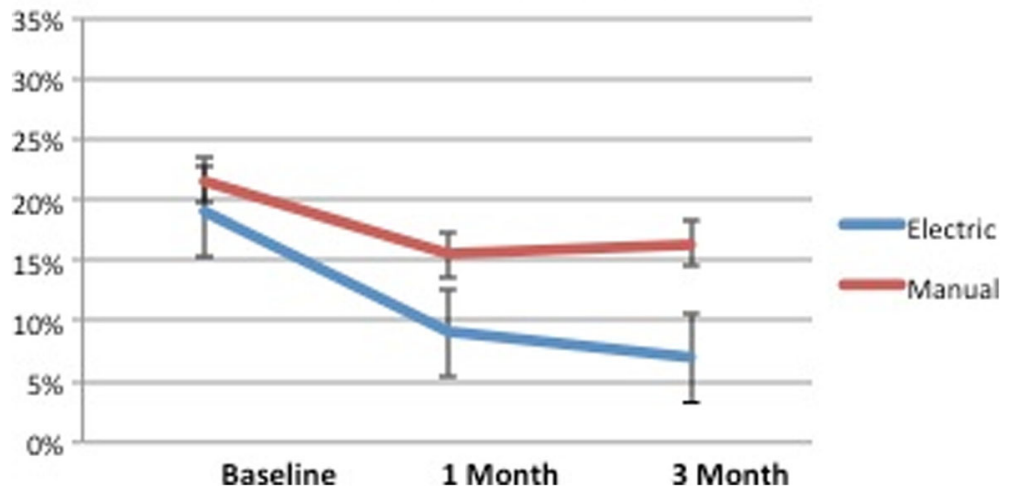

Fig. 6 BoP on natural teeth. While the control group shows a mild increase between 1 month and 3 months, the test group values decrease during all the duration of the study

than $3 \mathrm{~mm}$, patients presenting deeper pockets were included, which might represent a limit of the study. The prophylaxis performed at the beginning of the study, in fact, could not remove adequately the plaque present in the deepest area of these pockets. This prevented the achievement of a "level 0 " of PI and $\mathrm{BoP}$ and, at the same time, promoted a faster re-colonization. During this time, patients also improved their skills with the electric toothbrush, which have also might influence their motivation. These factors could explain the reduction of PI observed in the second part of the study on the electric toothbrush groups and, sequentially, of the BoP as inflammatory index caused by the presence of plaque itself. The efficacy of the electric toothbrush can be related to the easiness of use and the complexity of artificial movement (rotating-oscillatory), which has been demonstrated to be more effective in plaque removal with respect to the manual toothbrush as reported by many authors [14, 25, 27]. Many authors observed a $0.3-\mathrm{mm}$ reduction of probing depth after at least 12-month observation period in the patients using the electric toothbrush $[26,28]$. Despite in the present study it was observed only $0.15 \mathrm{~mm}$ of mean probing reduction for dental implants, our observation was limited only to a 3 -month period. This trend could be comparable to a $0.3-\mathrm{mm}$ reduction in 12 months, as observed in the previous studies. However, a similar trend was also detected in the control group so the electric toothbrush cannot be directly related to the PPD reduction.

At the end of the present study, electric toothbrush groups showed plaque and bleeding values lower (PI and BoP on teeth) or at least without significative differences (BoP on implants) than the control group. These data may suggest how the use of electric toothbrush, associated to the dedicate heads, can be an effective method for plaque and bleeding reduction.

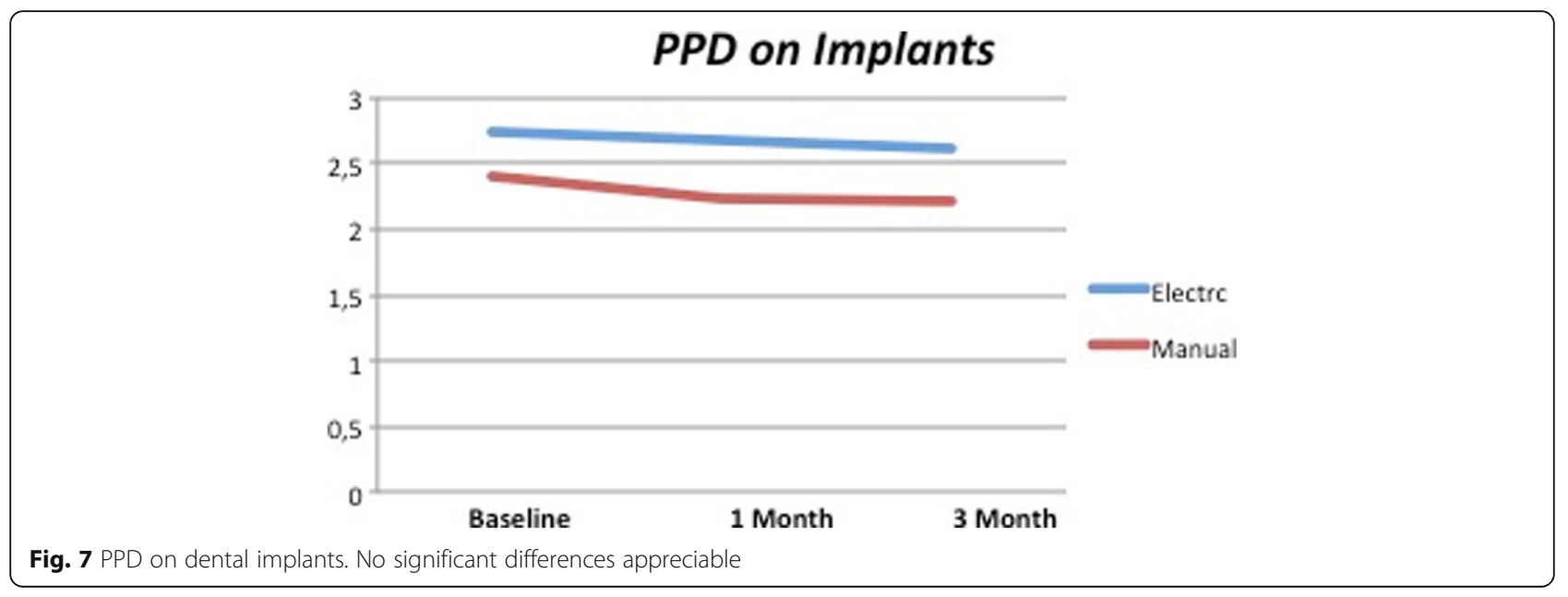




\section{PPD on Teeth}

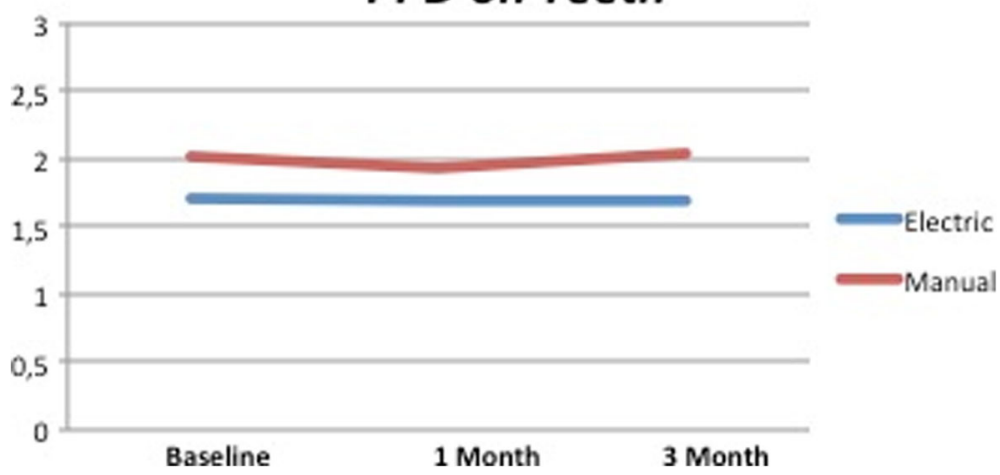

Fig. 8 PPD on natural teeth. No significant differences appreciable

\section{Conclusion}

The oscillating-rotating toothbrush can be used for the plaque and bleeding control around both natural teeth and dental implants. It has also been shown how the toothbrush head designed for dental implant can be effective in plaque removing of the peri-implant tissues.

\section{Abbreviations}

BoP: Bleeding on probing; PI: Plaque index; PPD: Pocket probing depth

\section{Acknowledgements}

Not applicable

\section{Funding}

The authors declare no funds for the research.

\section{Availability of data and materials}

Mean data of PI, BOP, and PPD collected from 80 periodontal charts are shown in Table 1.

\section{Authors' contributions}

CM and FS designed the study; GA and DP performed the patient treatment and data collection. FS edited the manuscript. GBG performed the data analysis. All authors read and approved the final version of the manuscript.

\section{Authors' information}

Not applicable

\section{Ethics approval and consent to participate}

This study was conducted in compliance with the principles of the Declaration of Helsinki, and the approval of the ethics committee required for the study was obtained from the Ethics Committee of the IRCCS Ospedale Maggiore Policlinico di Milano, Fondazione Ca' Granda. The procedures to be performed were explained in detail, and the patients signed the consent form.

\section{Consent for publication}

Not applicable

\section{Competing interests}

Giuseppe Allocca, Diana Pudylyk, Fabrizio Signorino, Giovanni Battista Grossi, and Carlo Maiorana declare that they have no competing interests.

\section{Publisher's Note}

Springer Nature remains neutral with regard to jurisdictional claims in published maps and institutional affiliations.

\section{Author details}

${ }^{1}$ Center for Edentulism and Jaw Atrophies, Maxillofacial Surgery and Dentistry Unit, Fondazione IRCCS Cà Granda - Ospedale Maggiore Policlinico, University of Milan, Via Commenda 10, 20122 Milan, Italy. ${ }^{2}$ Oral Surgery, Maxillofacial Surgery and Dentistry Unit, Fondazione IRCCS Cà Granda Ospedale Maggiore Policlinico, University of Milan, Via Commenda 10, 20122 Milan, Italy.

Received: 12 April 2018 Accepted: 24 October 2018

Published online: 10 December 2018

References

1. Pjetursson BE, Lang NP. Prosthetic treatment planning on the basis of scientific evidence. J Oral Rehabil. 2008;35(Suppl 1):72-9. https://doi.org/10. 1111/j.1365-2842.2007.01824.x PubMed PMID: 18181936.

2. Jung RE, Pjetursson BE, Glauser R, Zembic A, Zwahlen M, Lang NP. A systematic review of the 5 -year survival and complication rates of implant-supported single crowns. Clin Oral Implants Res. 2008;19(2):119-30. https://doi.org/10. 1111/j.1600-0501.2007.01453.x Epub 2007/12/07. PubMed PMID: 18067597.

3. Zhuang LF, Watt RM, Mattheos N, Si MS, Lai HC, Lang NP. Periodontal and peri-implant microbiota in patients with healthy and inflamed periodontal and peri-implant tissues. Clin Oral Implants Res. 2016;27(1):13-21. https:// doi.org/10.1111/clr.12508 Epub 2014/11/14. PubMed PMID: 25399962.

4. Lindquist LW, Rockler B, Carlsson GE. Bone resorption around fixtures in edentulous patients treated with mandibular fixed tissue-integrated prostheses. J Prosthet Dent. 1988;59(1):59-63 PubMed PMID: 3422305.

5. Karoussis IK, Kotsovilis S, Fourmousis I. A comprehensive and critical review of dental implant prognosis in periodontally compromised partially edentulous patients. Clin Oral Implants Res. 2007;18(6):669-79. https://doi.org/10.1111/j 1600-0501.2007.01406.x Epub 2007/09/13. PubMed PMID: 17868376.

6. van der Weijden GA, Hioe KP. A systematic review of the effectiveness of self-performed mechanical plaque removal in adults with gingivitis using a manual toothbrush. J Clin Periodontol. 2005;32(Suppl 6):214-28. https://doi. org/10.1111/j.1600-051X.2005.00795.x PubMed PMID: 16128840.

7. Dalago HR, Schuldt Filho G, Rodrigues MA, Renvert S, Bianchini MA. Risk indicators for peri-implantitis. A cross-sectional study with 916 implants. Clin Oral Implants Res. 2017;28(2):144-50. https://doi.org/10.1111/clr.12772 Epub 2016/01/11. PubMed PMID: 26754342.

8. Lindquist LW, Carlsson GE, Jemt T. A prospective 15-year follow-up study of mandibular fixed prostheses supported by osseointegrated implants. Clinical results and marginal bone loss. Clin Oral Implants Res. 1996;7(4):329-36 PubMed PMID: 9151599.

9. Fransson C, Lekholm U, Jemt T, Berglundh T. Prevalence of subjects with progressive bone loss at implants. Clin Oral Implants Res. 2005;16(4):440-6. https://doi.org/10.1111/j.1600-0501.2005.01137.x PubMed PMID: 16117768.

10. Costa FO, Takenaka-Martinez S, Cota LO, Ferreira SD, Silva GL, Costa JE. Periimplant disease in subjects with and without preventive maintenance: a 5year follow-up. J Clin Periodontol. 2012;39(2):173-81. https://doi.org/10. 1111/j.1600-051X.2011.01819.x Epub 2011/11/23. PubMed PMID: 22111654. 
11. Quirynen $M$, De Soete $M$, van Steenberghe D. Infectious risks for oral implants: a review of the literature. Clin Oral Implants Res. 2002;13(1):1-19 PubMed PMID: 12005139.

12. Roos-Jansåker AM, Renvert S, Egelberg J. Treatment of peri-implant infections: a literature review. J Clin Periodontol. 2003;30(6):467-85 PubMed PMID: 12795785.

13. Ho HP, Niederman R. Effectiveness of the Sonicare sonic toothbrush on reduction of plaque, gingivitis, probing pocket depth and subgingival bacteria in adolescent orthodontic patients. J Clin Dent 1997;8(1 Spec No): 15-19. PubMed PMID: 9487840.

14. Wolff L, Kim A, Nunn M, Bakdash B, Hinrichs J. Effectiveness of a sonic toothbrush in maintenance of dental implants. A prospective study. J Clin Periodontol. 1998;25(10):821-8 PubMed PMID: 9797055

15. Cronin M, Dembling W, Warren PR, King DW. A 3-month clinical investigation comparing the safety and efficacy of a novel electric toothbrush (Braun Oral-B 3D Plaque Remover) with a manual toothbrush. Am J Dent 1998;11(Spec No):S17-S21. PubMed PMID: 10530095

16. Quirynen M, Vervliet E, Teerlinck J, Darius P, van Steenberghe D. Mediumand long-term effectiveness of a counterrotational electric toothbrush on plaque removal, gingival bleeding, and probing pocket depth. Int J Periodontics Restorative Dent. 1994;14(4):364-77 PubMed PMID: 7814228.

17. Swierkot $K$, Brusius $M$, Leismann D, Nonnenmacher C, Nüsing R, Lubbe $D$, et al. Manual versus sonic-powered toothbrushing for plaque reduction in patients with dental implants: an explanatory randomised controlled trial. Eur J Oral Implantol. 2013;6(2):133-44 PubMed PMID: 23926585.

18. Hellstadius K, Asman B, Gustafsson A. Improved maintenance of plaque control by electrical toothbrushing in periodontitis patients with low compliance. J Clin Periodontol. 1993;20(4):235-7 PubMed PMID: 8473531.

19. Tawse-Smith A, Duncan WJ, Payne AG, Thomson WM, Wennström JL. Relative effectiveness of powered and manual toothbrushes in elderly patients with implant-supported mandibular overdentures. J Clin Periodontol. 2002;29(4):275-80 PubMed PMID: 11966923.

20. Chang M, Wennström JL, Odman P, Andersson B. Implant supported singletooth replacements compared to contralateral natural teeth. Crown and soft tissue dimensions. Clin Oral Implants Res. 1999;10(3):185-94 PubMed PMID: 10522178

21. Berglundh T, Lindhe J. Dimension of the periimplant mucosa. Biological width revisited. J Clin Periodontol. 1996;23(10):971-3 PubMed PMID: 8915028.

22. Berglundh T, Lindhe J, Ericsson I, Marinello CP, Liljenberg B, Thomsen P. The soft tissue barrier at implants and teeth. Clin Oral Implants Res. 1991;2(2): 81-90 PubMed PMID: 1809403.

23. Berglundh T, Abrahamsson I, Welander M, Lang NP, Lindhe J. Morphogenesis of the peri-implant mucosa: an experimental study in dogs. Clin Oral Implants Res. 2007;18(1):1-8. https://doi.org/10.1111/j.1600-0501. 2006.01380.x PubMed PMID: 17224016.

24. Cagna DR, Massad JJ, Daher T. Use of a powered toothbrush for hygiene of edentulous implant-supported prostheses. Compend Contin Educ Dent. 2011;32(4):84-8 PubMed PMID: 21661663

25. Truhlar RS, Morris HF, Ochi S. The efficacy of a counter-rotational powered toothbrush in the maintenance of endosseous dental implants. J Am Dent Assoc. 2000;131(1):101-7 PubMed PMID: 10649881.

26. Vandekerckhove B, Quirynen M, Warren PR, Strate J, van Steenberghe D. The safety and efficacy of a powered toothbrush on soft tissues in patients with implant-supported fixed prostheses. Clin Oral Investig. 2004;8(4):206-10. https:// doi.org/10.1007/s00784-004-0278-z Epub 2004/07/28. . PubMed PMID: 15583919.

27. Kurtz B, Reise M, Klukowska M, Grender JM, Timm H, Sigusch BW. A randomized clinical trial comparing plaque removal efficacy of an oscillating-rotating power toothbrush to a manual toothbrush by multiple examiners. Int J Dent Hyg. 2016;14(4):278-83. https://doi.org/10.1111/idh. 12225 Epub 2016/05/06. PubMed PMID: 27151435.

28. Rasperini G, Pellegrini G, Cortella A, Rocchietta I, Consonni D, Simion M. The safety and acceptability of an electric toothbrush on peri-implant mucosa in patients with oral implants in aesthetic areas: a prospective cohort study. Eur J Oral Implantol. 2008;1(3):221-8 PubMed PMID: 20467624.

29. Parizi MT, Mohammadi TM, Afshar SK, Hajizamani A, Tayebi M. Efficacy of an electric toothbrush on plaque control compared to two manual toothbrushes. Int Dent J. 2011;61(3):131-5. https://doi.org/10.1111/j.1875595X.2011.00029.x PubMed PMID: 21692783.

30. Heasman PA, Stacey F, Heasman L, Sellers P, Macgregor ID, Kelly PJ. A comparative study of the Philips HP 735, Braun/Oral B D7 and the Oral B 35 advantage toothbrushes. J Clin Periodontol. 1999:26(2):85-90 PubMed PMID: 10048641.

\section{Submit your manuscript to a SpringerOpen ${ }^{\circ}$ journal and benefit from:}

- Convenient online submission

- Rigorous peer review

- Open access: articles freely available online

- High visibility within the field

- Retaining the copyright to your article

Submit your next manuscript at $\boldsymbol{\nabla}$ springeropen.com 